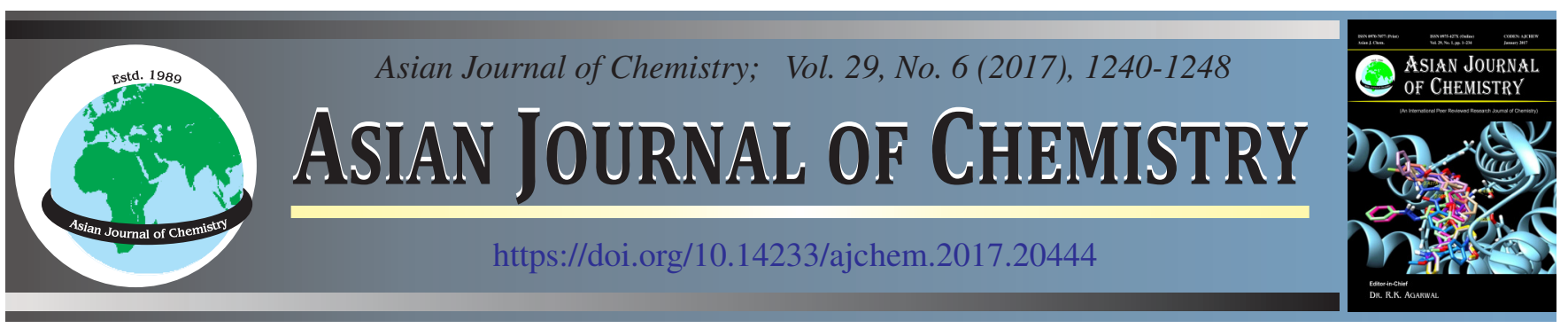

\title{
Characterization and Biological Activities of Silver Nanoparticles Synthesized from Stems of Sarcocephalus latifolius (Sm) E.A. Bruce and Massularia acuminata (G. Don) Bullock ex Hoyl. (Rubiaceae)
}

Emmanuel Olusegun Ajayi", Samuel Wale Odeyemi, Gloria Aderonke Otunola and Anthony Jide Afolayan*

Medicinal Plants and Economic Development (MPED) Research Center, Department of Botany, University of Fort Hare, Alice 5700, South Africa

*Corresponding authors: E-mail: EAjayi@ufh.ac.za; Aafolayan@ufh.ac.za

Received: 14 December 2016;

Accepted: 16 March 2017;

Published online: 10 April 2017;

AJC-18333

Silver nanoparticles (AgNPs) have been synthesized from the stems of Sarcocephalus latifolius (SL) and Massularia acuminata (MA) and characterized for their sizes and shapes using scanning electron microscopy (SEM) and transmission electron microscopy (TEM). Complete formations of the AgNPs were observed with colour change from colourless to brownish-black. Fourier transform infrared spectroscopy (FT-IR) and energy dispersive X-ray spectroscopy (EDS/EDX) were conducted to detrmine the various functional groups and the concentration of metal ions of the molecules. The data analysis showed sizes of 3-41 nm and 3-37 nm, spherical shaped nanoparticles for Sarcocephalus latifolius and Massularia acuminata, respectively as revealed by TEM, complementing the results for SEM. FT-IR identifies ethylene groups as the reducing and capping agents for the formation of the nanoparticles. The X-ray diffraction pattern confirmed the presence of silver crystallites and as well as their sizes, confirming the TEM results. Silver nanoparticles exhibited not too good potentials as free radical scavengers when compared to the standard drugs. The synthesized AgNPs in suspension showed activity against Gram-positive and Gram-negative bacteria with minimum inhibitory concentrations (MICs) to be in the range from 62.5 to 250 $\mu \mathrm{g} / \mathrm{mL}$. In summary, the synthesized AgNPs showed acceptable sizes and shapes of nanoparticles.

Keywords: Silver nanoparticles, Sarcocephalus latifolius, Massularia acuminata.

\section{INTRODUCTION}

Silver nanoparticles (AgNPs) have been the subjects of researchers due to their unique properties such as size and shape, optical, antimicrobial and electrical properties. The emergence of nanotechnology and the production of nanomedicinal values from different sources had proven to be of great value in the field of biomedicine. Nanotechnology is a very important field of modern research dealing with the design, synthesis and manipulation of particle structures ranging from 1-100 $\mathrm{nm}[1]$. In a chemical reduction process, silver nanoparticles are obtained along with toxic residuals which are undesirable for any sort of biomedical application. As a result, alternative methods are sought for the synthesis of silver nanoparticles without any known toxic by-products. Silver nanoparticles have also been synthesized from bacteria [2], fungus [3] and plants [4,5]. Synthesis of silver nanoparticles has been extensively studied using chemical and physical methods, but the development of reliable technology to produce nanoparticles is an important aspect of nanotechnology [6]. The biological methods have been suggested as eco-friendly alternatives to chemical methods [7]. The plants or their extracts which act as reducing and capping agents for nanoparticles synthesis are more advantageous over biological processes [8], because the elaborate process of culturing and maintenance of the cell are eliminated. Plant-mediated nanoparticles synthesis is preferred as a result of its cost effectiveness, environmentally friendly and safe for human therapeutic use [9]. Different parts of plant materials have been studied for the synthesis of silver, gold, platinum and titanium nanoparticles in different sizes and shapes [10]. Such parts include the extracts [11], fruit [12], bark [13], fruit peels [14] and callus [15].

Sarcocephalus latifolius (SL) belongs to the family Rubiaceae, locally known as Egbesi (Yoruba), Tafashiya or tuwon biri (Hausa), Ubuluinu (Igbo) in Nigerian languages and African peach in English [16]. Sarcocephalus latifolius has been identified with many pharmacological activities, making it attractive in herbal market [17]. Some common pharmacological attributes of the plant include the control of malaria [18], a disease endemic in West Africa and the tropical regions of the world; cardiovascular, spasmolytic and antiparasitic effects [19,20]. Other attributes of Sarcocephalus latifolia include its use as tonic and in fever, diarrhea, dysentry 
and dental problems and is suitable for use as chewing sticks, as antihypertensive [21] and antimicrobial [22].

Massularia acuminata (MA) is a chewing stick widely used for oral and dental care among the rural natives in the tropical West Africa [23]. Almost the entire rural population of Nigeria uses chewing sticks for orodental hygiene [24]. Incidentally, chewing sticks are recommended for oral hygiene by the World Health Organization [25]. Some of the chewing sticks or their extracts are also used in the ethnomedical treatment of oral infections [26]. The advancement of the modern tooth brushes can be traced back to chewing sticks used by the Babylonians, 7000 years ago [27].

A lot of work has been done on various parts of both Sarcocephalus latifolius and Massularia acuminata, but research on their synthesis as nanoparticles have not been documented. This study focusses on the synthesis of their silver nanoparticles, their characterization and also evaluation of their antioxidant and antibacterial activities.

\section{EXPERIMENTAL}

The materials used include Nutrient agar (SAARCHEM, Gauteng SA), Nutrient broth (DIFCO, California USA), silver nitrate, dimethyl sulfoxide (DMSO), ABTS, DPPH, potassium persulfate were purchased from Sigma-Aldrich. All the bacteria cultures were obtained from the Microbiology unit of MPED Research Center. Fresh stems of Sarcocephalus latifolius and Massularia acuminata were purchased from local herb sellers in Ibadan, Oyo State, Nigeria. The samples were identified and authenticated by Professor Don Grierson of the Botany Department, University of Fort Hare. The stems of Massularia acuminata and Sarcocephalus latifolius were washed thoroughly under running tap water to remove dirt. The samples were dried and later pulverized into a fine powder with a grinder. The powders were stored in air tight aseptic container until further use.

Preparation of silver nanoparticles: $20 \mathrm{~g}$ Each of pulverized $S$. latifolius and M. acuminata were weighed into a sterile $250 \mathrm{~mL}$ conical flask. $100 \mathrm{~mL}$ of deionized water was added separately. Mixture was stirred at $60{ }^{\circ} \mathrm{C}$ for $10 \mathrm{~min}$ in water bath. It was allowed to cool and filtered under vacuum with Whatman filter paper No. 1. The filterate of the samples were stored at $4{ }^{\circ} \mathrm{C}$ for further experiments. $15 \mathrm{~mL}$ of the prepared extracts were added to $45 \mathrm{~mL}$ of aqueous $\mathrm{AgNO}_{3}$
( $0.1 \mathrm{M}$ solution) at room temperature. The mixture was stirred continously for $15 \mathrm{~min}$. The solution obtained was kept in the dark to prevent autooxidation of silver. The reduction was completed after $24 \mathrm{~h}$ with the appearance of brownish-black colour which confirms the formation of silver nanoparticles by $S$. latifolius and M. acuminata stem extracts (Fig. 1). The silver nanoparticles were centrifuged at $3000 \mathrm{rpm}$ for $10 \mathrm{~min}$. The resulting pellets were dried in an oven at $100{ }^{\circ} \mathrm{C}$ for $24 \mathrm{~h}$. The dried silver nanoparticles of S. latifolius and M. acuminata were stored in a tight container away from light until further use.

UV-visible spectrometric analysis: The UV-visible spectra of the synthesized silver nanoparticles were recorded as a function of wavelength using UV-visible spectrophotometer (UV-3000 PC spectrometer) operated at a resolution of $0.5 \mathrm{~nm}$. The reduction of silver was measured periodically at 300-700 nm. A spectrum of silver nanoparticles was plotted with wavelength on $\mathrm{x}$-axis and absorbance on $\mathrm{y}$-axis.

Fourier transform infrared analysis: FT-IR measurements of the silver nanoparticles were carried out to identify the major functional groups in the synthesized compounds. FT-IR measurements were carried out using JASCO FT-IR 4100 by employing $\mathrm{KBr}$ disc technique. The FT-IR spectra were collected from 50 scans at a resolution of $4 \mathrm{~cm}^{-1}$ in the transmission mode (4000-440 $\left.\mathrm{cm}^{-1}\right)$.

Scanning electron microscopy-energy dispersive X-ray spectrometry: For SEM and elemental analysis the samples were prepared by mounting respective nanoparticles on stub using double-sided tape. They were later coated with $\mathrm{Au} / \mathrm{Pd}$ using the Eiko IB. 3 Ion Coater. They were observed using JOEL-JSM-6390 LVSEM at a rating voltage of 15-20 kV at different magnifications as indicated on the SEM images.

Transmission electron microscope: Transmission electron microscopy technique was used to visualize the morphology of the synthesized silver nanoparticles. The TEM micrographs were obtained using a Zeiss LIBRA ${ }^{\circledR} 120$ TEM operating at $80 \mathrm{kV}$. A drop of the silver nanoparticles in methanol was loaded on a carbon-coated copper grid and allowed to dry at room temperature and then analyzed.

$\mathrm{X}$-ray diffraction analysis of silver nanoparticles: The $\mathrm{X}$-ray diffraction of the nanoparticles were recorded on a Brucker D8 Advanced, equipped with a proportional counter $\mathrm{CuK}_{\alpha}$ radiation $(\lambda=1.5405 \AA$, nickel filter), operated at the voltage of $45 \mathrm{kV}$ and current of $30 \mathrm{~mA}$.

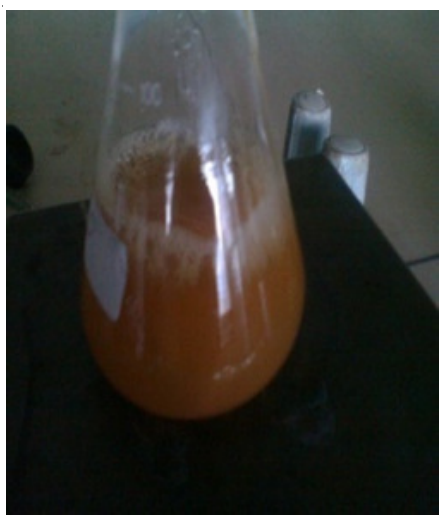

SL1

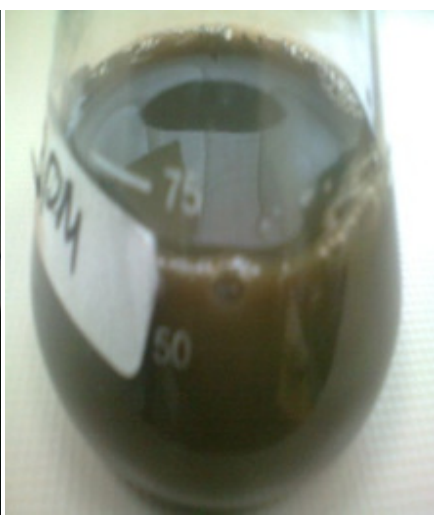

SL2

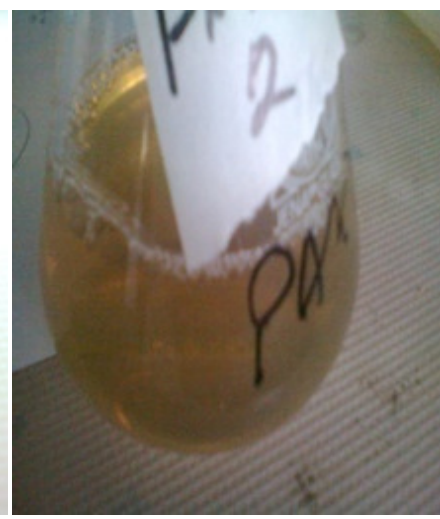

MA1

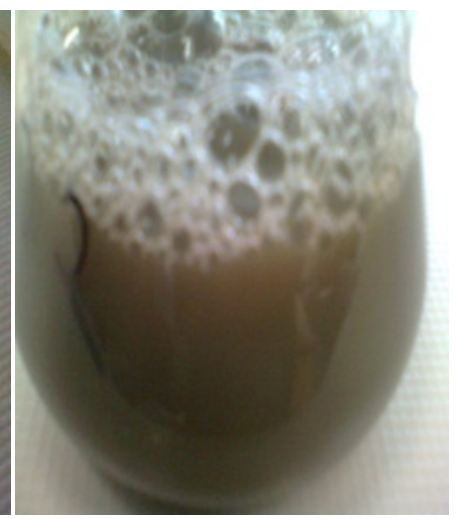

MA2

Fig. 1. S. latifolius (SL) and M. acuminata (MA) root extracts with $0.1 \mathrm{M} \mathrm{AgNO}_{3}$ solution before and after formation of silver nanoparticles 


\section{Antioxidant assay}

Scavenging activity of 1,1-diphenyl-2-picrylhydrazyl (DPPH) radical: DPPH radical scavenging activity evaluation is a standard assay in antioxidant activity studies. It is regarded as a rapid method for screening radical scavenging activity of specific compounds [28]. The method of Odeyemi et al. [29] using microtitre plate was used for the determination of DPPH radical scavenging activity. $100 \mu \mathrm{L}$ of methanol was added into the wells with the exception of second (B) and third (C) rows. $200 \mu \mathrm{L}$ of the silver nanoparticles $(0.5 \mathrm{mg} / \mathrm{mL})$ and standard drugs prepared in methanol were added in triplicates to the third row (starting from the first column) and, transferring 100 $\mu \mathrm{L}$ into the second well of the same column and the procedure was repeated up to the $7^{\text {th }}$ well of the same column and the last $100 \mu \mathrm{L}$ from the $7^{\text {th }}$ well was discarded. Various concentrations of the silver nanoparticles and the standards, ranging from 0.01 $\mathrm{mg} / \mathrm{mL}$ to $0.5 \mathrm{mg} / \mathrm{mL}$ were prepared in the wells, following a two-fold dilution method. A solution of $0.135 \mathrm{mM} \mathrm{DPPH}$ radical was prepared in methanol. $100 \mu \mathrm{L}$ of this solution was added into all the wells. The reaction mixture was then vortexed thoroughly and left in the dark at room temperature for $30 \mathrm{~min}$ and the absorbance measured spectrophotometrically at 517 $\mathrm{nm}$. The actual decrease in absorbance was measured against that of the control. The scavenging ability of the nanoparticles was calculated using the equation:

DPPH scavenging activity $(\%)=\left(\frac{\mathrm{Abs}_{\text {control }}-\mathrm{Abs}_{\text {sample }}}{\mathrm{Abs}_{\text {control }}}\right) \times 100$ where $\mathrm{Abs}_{\text {control }}$ is the absorbance of DPPH + methanol and $\mathrm{Abs}_{\text {sample }}$ is the absorbance of DPPH + sample (nanoparticles/ standards).

2,2'-Azino-bis(3-ethylbenzthiazoline-6-sulfonic acid (ABTS) radical scavenging activity: The modified method described by Re et al. [30] was employed for the determination of ABTS scavenging activity. The stock solutions, comprising of $7 \mathrm{mM}$ ABTS solution and $2.4 \mathrm{mM}$ potassium persulfate solution were prepared. The working solution was later obtained by mixing the two stock solutions $(1: 1 \mathrm{v} / \mathrm{v})$ and allowed to react for $12 \mathrm{~h}$ in the dark at room temperature. The solution was then diluted by mixing $1 \mathrm{~mL} \mathrm{ABTS}{ }^{+}$solution with $60 \mathrm{~mL}$ of methanol to obtain an absorbance of $0.708 \pm 0.001$ units at $734 \mathrm{~nm}$ using the spectrophotometer. $100 \mu \mathrm{L}$ of methanol was added into all the wells with the exception of second (B) and third (C) rows. $200 \mu \mathrm{L}$ of the nanoparticles $(0.5 \mathrm{mg} / \mathrm{mL})$ or standard drugs prepared in methanol were added in triplicates to the third row (C). A two fold serial dilution was done by mixing the contents in each well of the third row (starting from the first column) and transferring $100 \mu \mathrm{L}$ into the second well of the same column and the procedure was repeated up to the $7^{\text {th }}$ well of the same column and the last $100 \mu \mathrm{L}$ from the $7^{\text {th }}$ well was discarded. Various concentrations of the plant nanoparticles and standards ranging from $0.01 \mathrm{mg} / \mathrm{mL}$ to $0.5 \mathrm{mg} / \mathrm{mL}$ were prepared in the wells, following the two-fold dilution method. The silver nanoparticles $(100 \mu \mathrm{L})$ and the control were allowed to react with $100 \mu \mathrm{L}$ of the $\mathrm{ABTS}^{+}$ solution and the absorbance was taken at $734 \mathrm{~nm}$ after $7 \mathrm{~min}$ using the spectrophotometer. The $\mathrm{ABTS}^{+}$scavenging capacity of the nanoparticles was then compared with that of the standard drugs. The percentage inhibition was calculated as follows:

$$
\text { ABTS scavenging activity }(\%)=\left(1-\frac{\mathrm{Abs}_{\text {sample }}}{\mathrm{Abs}_{\text {control }}}\right) \times 100
$$

where $\mathrm{Abs}_{\text {control }}$ is the absorbance of ABTS radical + methanol and $\mathrm{Abs}_{\text {sample }}$ is the absorbance of ABTS radical + sample (nanoparticles/standard drugs).

\section{Antibacterial screening}

Bacteria samples and culture preparation: Four reference strains of bacteria used in this study were chosen based on their pathological effects on humans. Gram-positive bacteria Enterococcus faecalis (ATCC: 29212), Bacillus cereus (ATCC: 10702) and Gram-negative bacteria Escherichia coli (ATCC: 25922) and Shigella flexneri (KZN) were obtained from the Microbiology Unit of MPED Research Centre, Botany Department, University of Fort Hare. The bacteria isolates were subcultured on nutrient agar (SAARCHEM, Gauteng SA) plates and incubated at $37^{\circ} \mathrm{C}$ for $24 \mathrm{~h}$. A loopful of bacterial cells from the nutrient agar plates was inoculated into $50 \mathrm{~mL}$ of a nutrient broth (DIFCO, California, USA) in a $250-\mathrm{mL}$ side arm Erlenmeyer flask and incubated at $37^{\circ} \mathrm{C}$ for $16 \mathrm{~h}$ with vigorous shaking in an orbital incubator (S150, UK). After incubation, the culture was diluted with fresh media to give an $\mathrm{OD}_{600 \mathrm{~nm}}$ of $0.1 .100 \mu \mathrm{L}$ of the cultured cells was added onto the plate and spread into an agar lawn using a sterile glass spreader.

Minimum inhibitory concentrations determination: The minimum inhibitory concentration (MIC) of the silver nanoparticles was determined using agar dilution method as described by NCCLS [31]. The bacterial strains were grown at $37^{\circ} \mathrm{C}$ overnight and maintained on nutrient agar. Inoculums of the test organisms were prepared in normal saline $(9 \mathrm{~g} / \mathrm{L})$ compared with $0.5 \mathrm{McF}$ arland standard to achieve $5 \times 10^{5}$ (CFU/mL). A stock solution of various synthesized silver nanoparticles were prepared in DMSO (Sigma) and further diluted in molten Mueller Hinton Agar (MHA) at $50{ }^{\circ} \mathrm{C}$ to give a final concentration ranged from $0.015625-0.25 \mathrm{mg} / \mathrm{mL}$. Ciprofloxacin was used instead of the AgNPs to serve as positive control. After pouring into the plates and allowed the agar to set, the plates were inoculated with standardized inocula of the test bacteria. The plates were further incubated at $37{ }^{\circ} \mathrm{C}$ for $24 \mathrm{~h}$ under aseptic conditions. The MIC was recorded as the lowest concentration at which no visible growth was observed.

\section{RESULTS AND DISCUSSION}

The stem nanoparticles of S. latifolius and M. acuminata have been shown to possess a broad variability of metabolites that may help in reduction of silver nitrate. The extracts from the two parts of plants were found to be reducing and stabilizing agents for the green synthesis of AgNPs. The preliminary confirmation for the formation of AgNPs was the visual observation of colour change of the reaction mixtures. The colour, noted by visual observation increased in intensity giving brown colour from the original yellow colour after $24 \mathrm{~h}$ of incubation (Fig. 1). Similar changes in colour have also been 
observed in previous studies [32,33], thereby confirming the completion of reaction between the stem extracts and $\mathrm{AgNO}_{3}$. The AgNPs formation by reducing silver ions was investigated by UV-visible spectroscopy. In this study, the formation of AgNPs was monitored by measuring UV-visible spectra at different time intervals (Fig. 2). As the time increased, the intensity of this absorbance increased, indicating increases in the amount of AgNPs produced from the mixture. The UV absorption spectrometric analysis of SL-AgNPs and MAAgNPs showed absorbance spectra at 450 and $390 \mathrm{~nm}$, respectively suggesting bioreduction of silver nitrate into silver nanoparticles. The broad absorption band at $450 \mathrm{~nm}$ for SLAgNPs is due to the surface plasmon resonance typical of silver nanoparticles [34]. The absorption peak in the UV-visible test at $450 \mathrm{~nm}$ for SL-AgNPs confirmed the formation of Ag. The sizes of the AgNPs are in the range of other reports $[35,36]$. However, the absorption band reported for MA-AgNPs occurred at around $390 \mathrm{~nm}$ which differs from for SL-AgNPs, but it showed the degree of changes in absorbance of the formation of Ag nanoparticles with respect to time.

The FT-IR measurements were carried out to identify the major functional groups present in the silver nanoparticles of the two plants. The representative spectra of the synthesized silver nanoparticles are shown in Fig. 3. The FT-IR spectrum showed sharp absorbance between 440 and $4000 \mathrm{~cm}^{-1}$ for both synthesized nanoparticles. There are other peaks in the spectrum at $774,814,1004,1303,1364,1566,1735,2916$, 2970 and 3251 which could be esters, ethers, carbonyl or aromatic compounds. The very strong absorption peak at 1365 and the strong absorption peak at 1306 for SL-AgNPs and MA-AgNPs respectively represents the presence of $\mathrm{NO}_{2}$ which may be from $\mathrm{AgNO}_{3}$ solution, the metal precursor involved in the silver nanoparticles synthesis process. Ethylene groups (=C-H, C=C) detected by FTIR have been reported by Li et al. [37]. The ethylene groups are capable of acting as reducing or capping agents. The two sharp absorption peaks for SL-AgNPs at $1736 \mathrm{~cm}^{-1}$ and $2970 \mathrm{~cm}^{-1}$ and also for MA-AgNPs at 1710 $\mathrm{cm}^{-1}$ and $2914 \mathrm{~cm}^{-1}$ (weak peaks) indicate the possible interaction between proteins and AgNPs. The absorption peak at $1736 \mathrm{~cm}^{-1}$ could be due to the amide bond due to the carbonyl group of a protein [38] and the peak at 3241 may be due to $\mathrm{OH}$ groups present in alcohols and phenolics [39]. Strong interaction of water with the surface of silver could be the reason for the O-H stretching mode peaks at 3254, 3241, 2970 $\mathrm{cm}^{-1}[40]$.

The shapes of the synthesized silver nanoparticles were analyzed by SEM. Fig. 4(a)-4(d) show the results of surface morphological and nanostructural studies using SEM and EDX images. The result for SL-AgNPs (Fig. 4a) showed that the particles are agglomerated and there was no clear shape. Similar result has been reported by Chitra and Annadurai [32]. The agglomeration might be due to the existence of large interaction between nanoparticles [41]. However, some spherical shapes could be observed at higher magnifications. Fig. $4 \mathrm{~b}$ represents the SEM image for MA-AgNPs, showing monodispersed spherical silver nanoparticles of varying sizes and shapes. Overall, the synthesized MA-AgNPs are spherical in shape, well dispersed with low agglomeration.

EDX analysis gives qualitative as well as quantitative status of elements that may be involved in formation of nanoparticles. The elemental profiles of synthesized nanoparticles for SLAgNPs and MA-AgNPs show higher count at $3 \mathrm{keV}$ due to

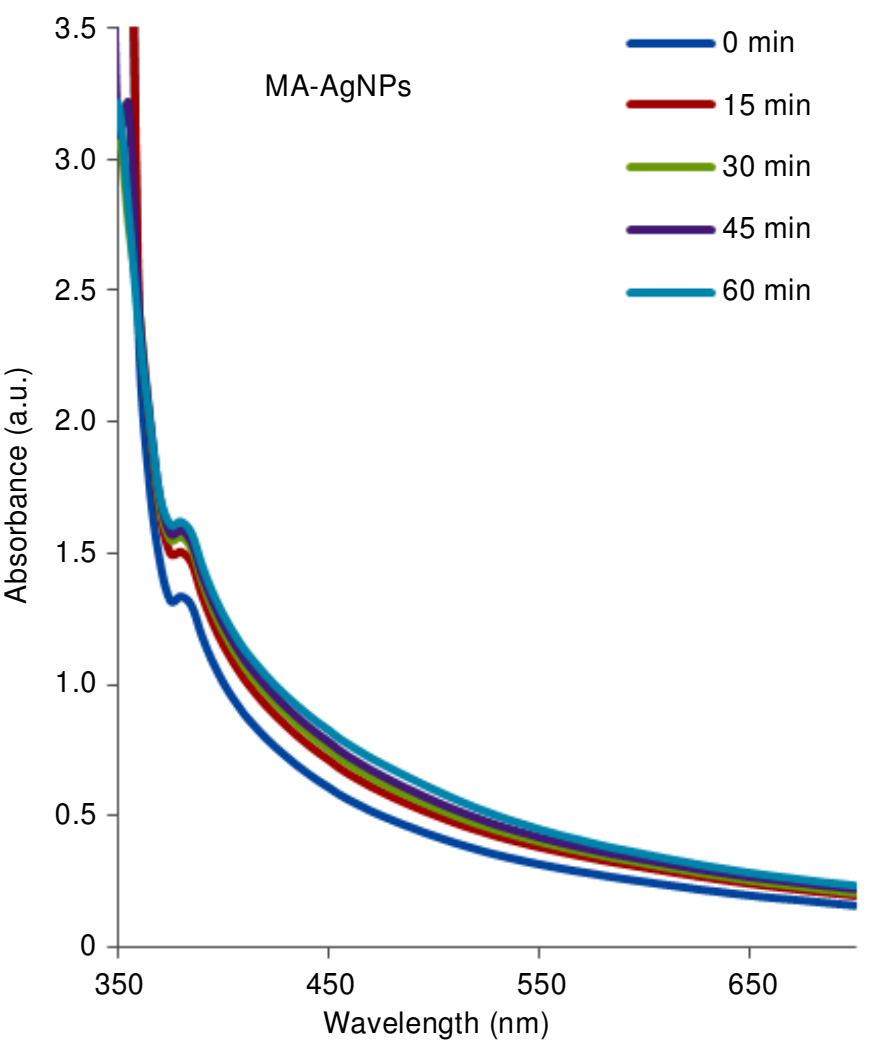

Wavelength $(\mathrm{nm})$

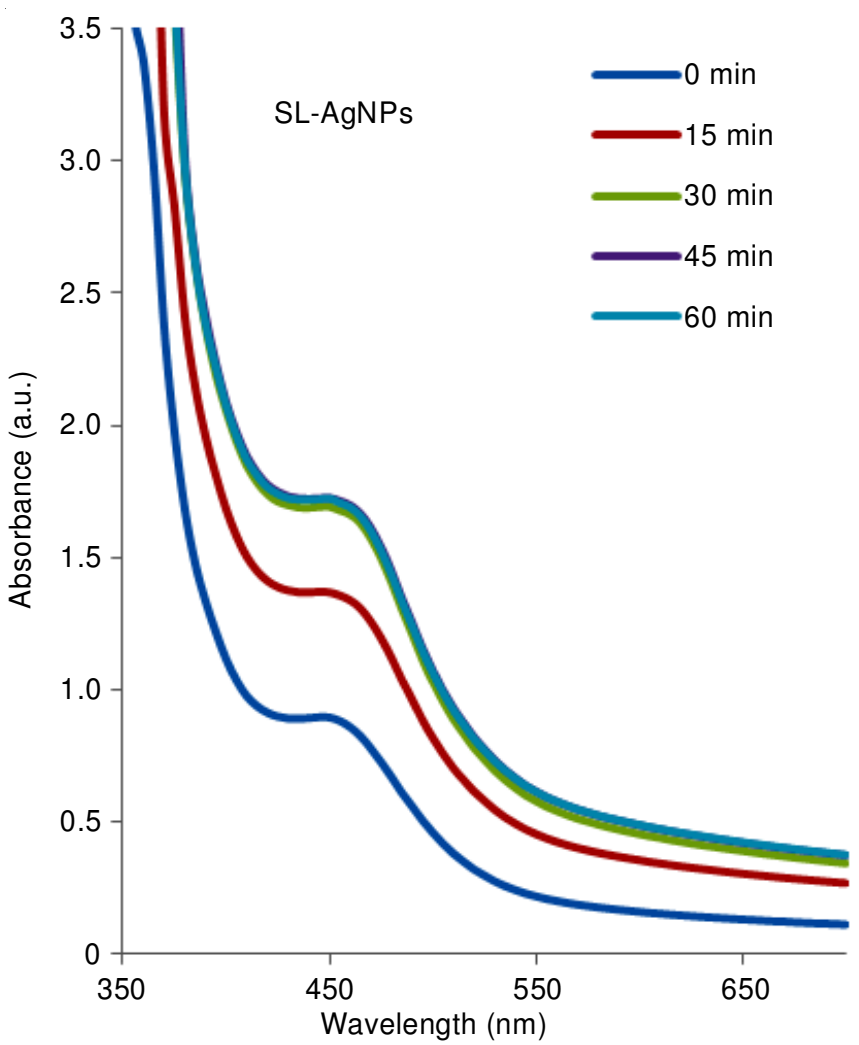

Fig. 2. UV-visible spectrum of AgNPs measured at different time intervals S. latifolius-AgNPs and M. acuminata-AgNPs 

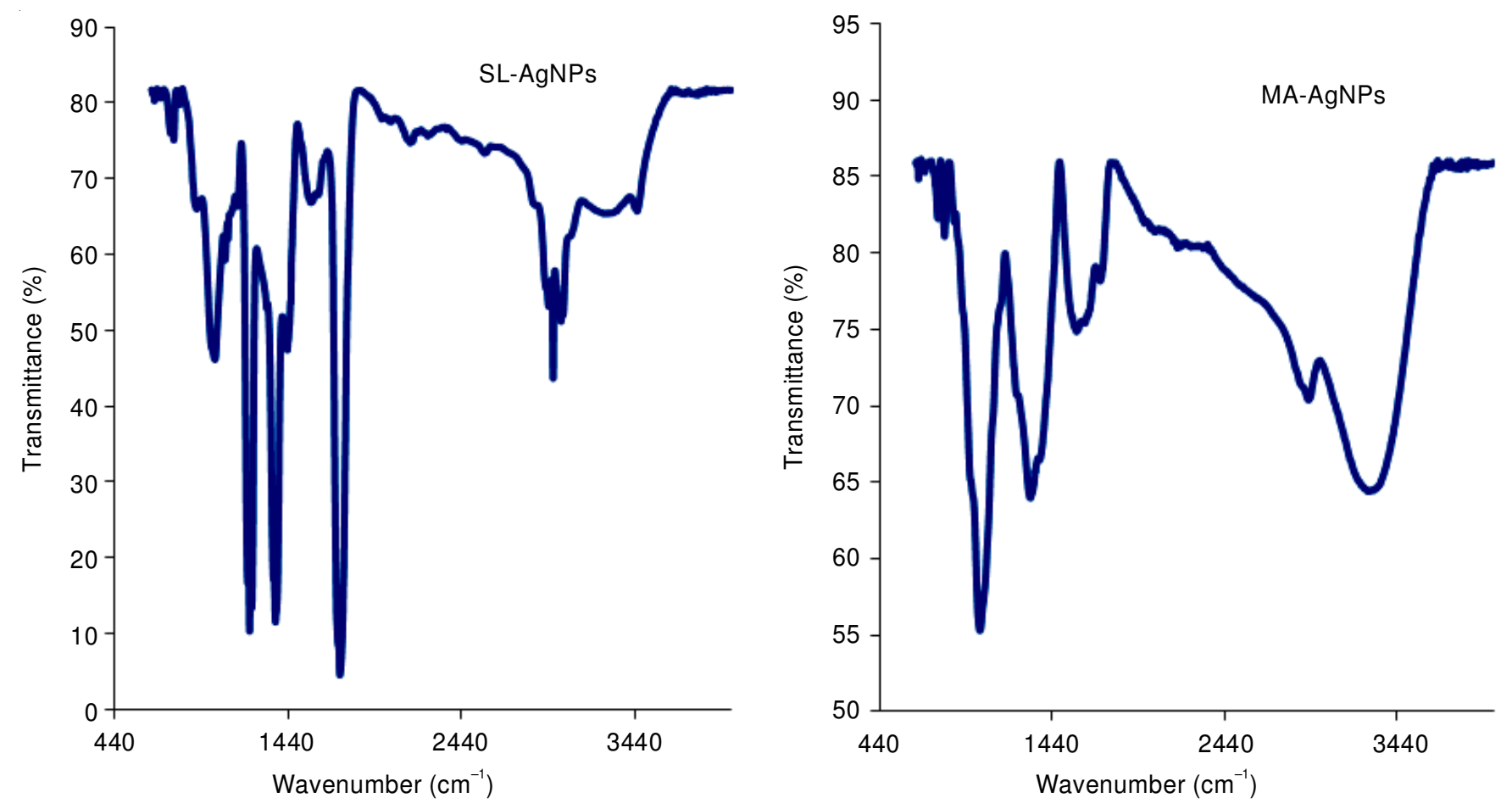

Fig. 3. Fourier transform infrared (FT-IR) spectrum of S. latifolius-AgNPs and M. acuminata- AgNPs
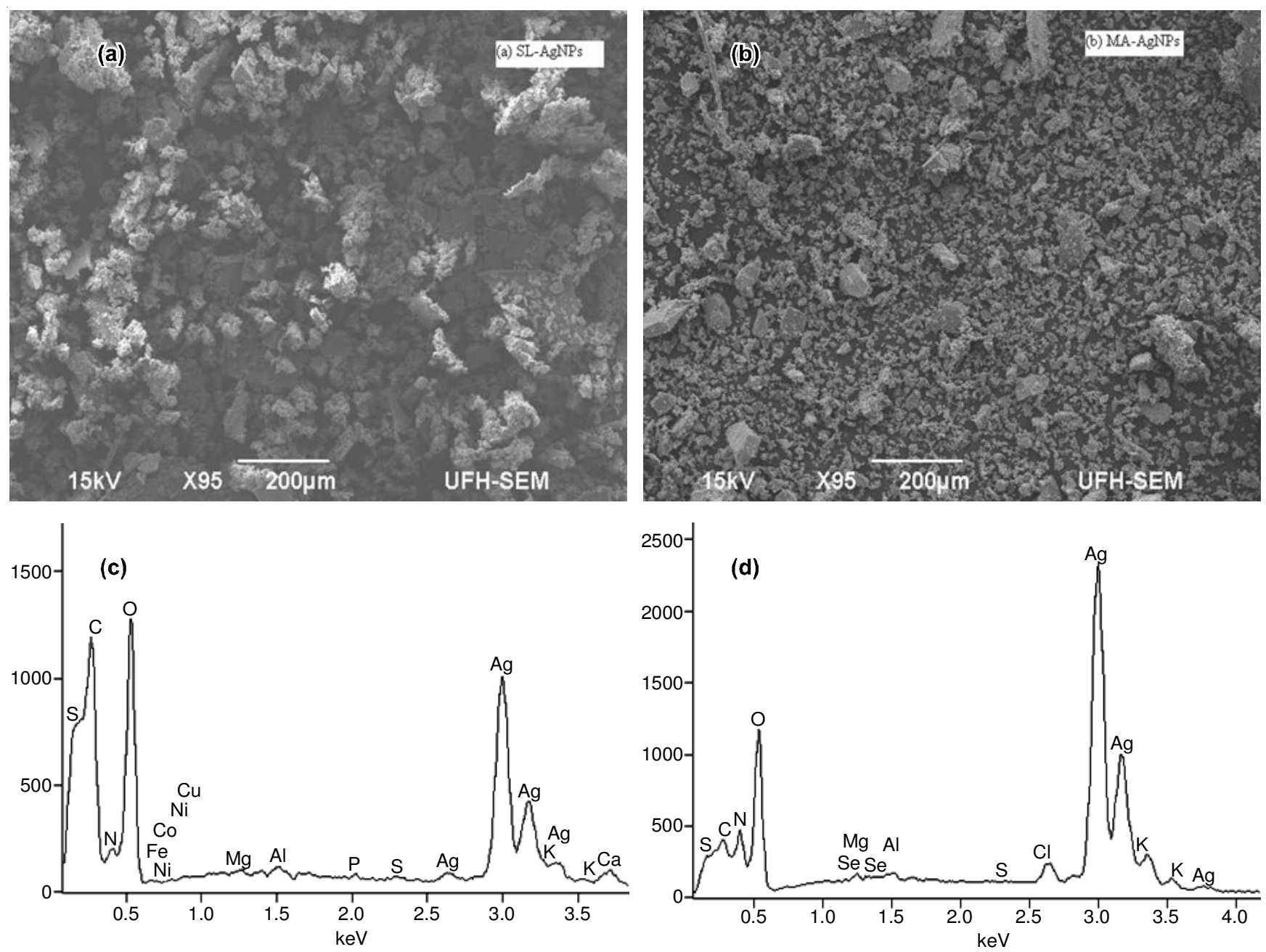

Fig. 4. SEM micrographs of (a) S. latifolius-AgNPs, (b) M. acuminata-AgNPs and EDX profiles of (c) S. latifolius-AgNPs and (d) M. acuminata-AgNPs 
silver, confirm the formation of silver nanoparticles (Fig. 4c and 4d). In general, metallic silver nanocrystals show typical optical absorption peak approximately at $3 \mathrm{keV}$ due to their surface plasmon resonance $[32,42,43]$. The elemental analysis of the silver nanoparticles shown in Fig. $4 \mathrm{c}$ and $4 d$ revealed highest proportion of silver followed by $\mathrm{O}, \mathrm{C}, \mathrm{S}, \mathrm{N}, \mathrm{Cl}$ and $\mathrm{K}$. Few other elements in trace amount were also present such as $\mathrm{Al}, \mathrm{Mg}$, Se and Ni.

The TEM images of the SL-AgNPs and MA-AgNPs appeared as spherical shaped, loosely distributed nanoparticles are shown in Fig. 5(a) and 4(b) respectively. The spherical shapes confirmed the results obtained by SEM. The data analysis showed sizes of silver nanoparticles in the range of 3-41 nm and 3-27 nm spherical shaped for SL-AgNPs and MA-AgNPs, respectively which may confer the ability to penetrate the cells/microbes and execute their bactericidal properties. Similar size ranges of AgNPs have been reported $[32,33,44]$.
The X-ray diffraction pattern of SL-AgNPS and MAAgNPs nano-particles was measured in the scan range of 50 to $120^{\circ}$. The crystalline sizes obtained from the X-ray diffractograms of the silver nanoparticles supported the results for TEM. The XRD spectrum confirmed the crystalline structure of the precipitate as silver (Ag) (Fig. 6a and b). The XRD data for SL-AgNPs show diffraction peaks at $2 \theta=64.71^{\circ}$, $77.68^{\circ}$ and $81.87^{\circ}$ corresponding to (2 20$)$, (3 111$)$ and (2 22 2) planes of pure silver ions indicating the biosynthesis of silver nanoparticles (Fig. 6a), whereas the diffraction peaks for MAAgNPs (Fig. 6b) at $2 \theta=64.22,77.41^{\circ}$ and $81.52^{\circ}$ which can be indexed to the (2 20$)$, ( 311 1) and (2 22 ) reflection planes, confirming the faced centred cubic crystalline structures of nanosilver [45].

In addition to the Bragg peaks representative of silver nanocrystals, additional peaks were also observed at $98.16^{\circ}$, $110.11^{\circ}, 111.03^{\circ}$ and $115.17^{\circ}$. These peaks are not assigned in the spectrum and may be due to the organic compounds
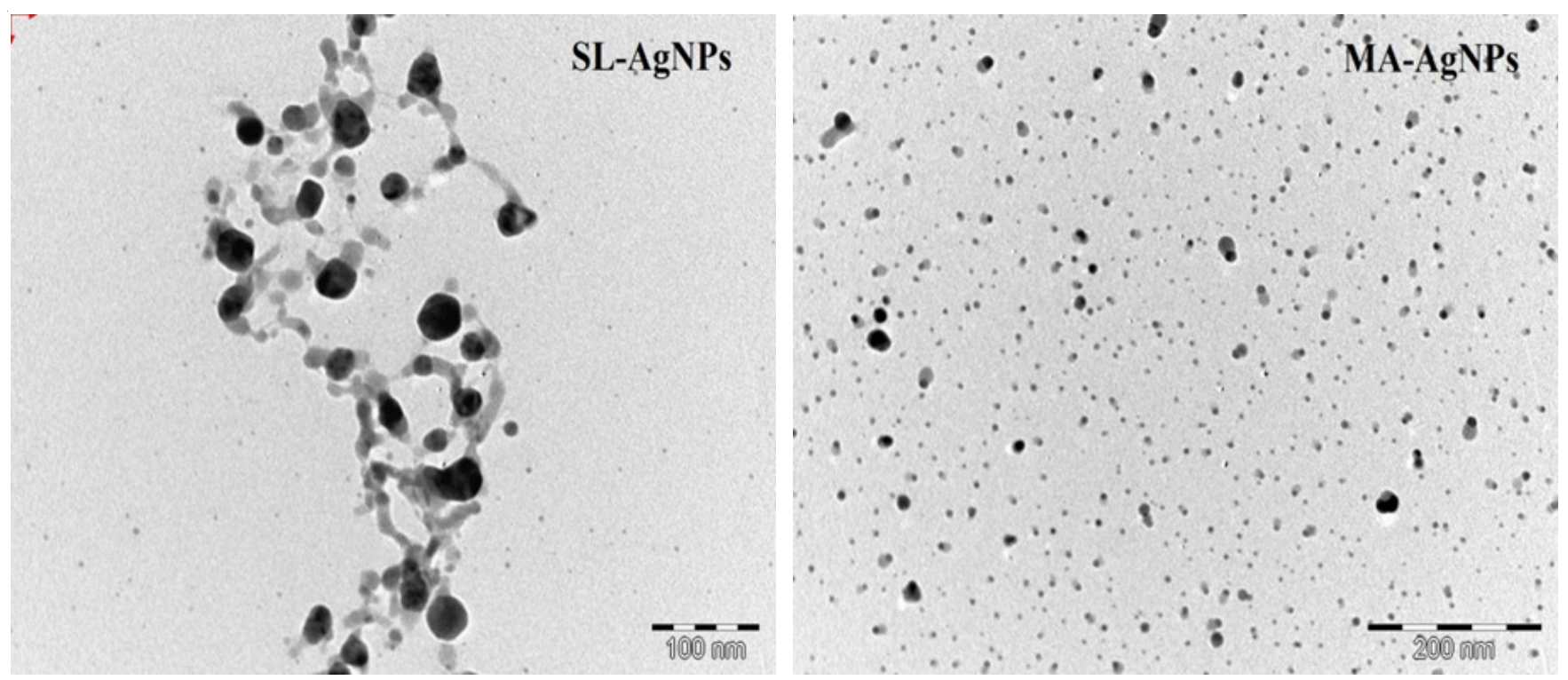

Fig. 5. Transmission electron microscopy images of S. latifolius-AgNPs and M. acuminata-AgNPs. Particles size was approximated to be around $28 \mathrm{~nm}$ and $11 \mathrm{~nm}$, respectively
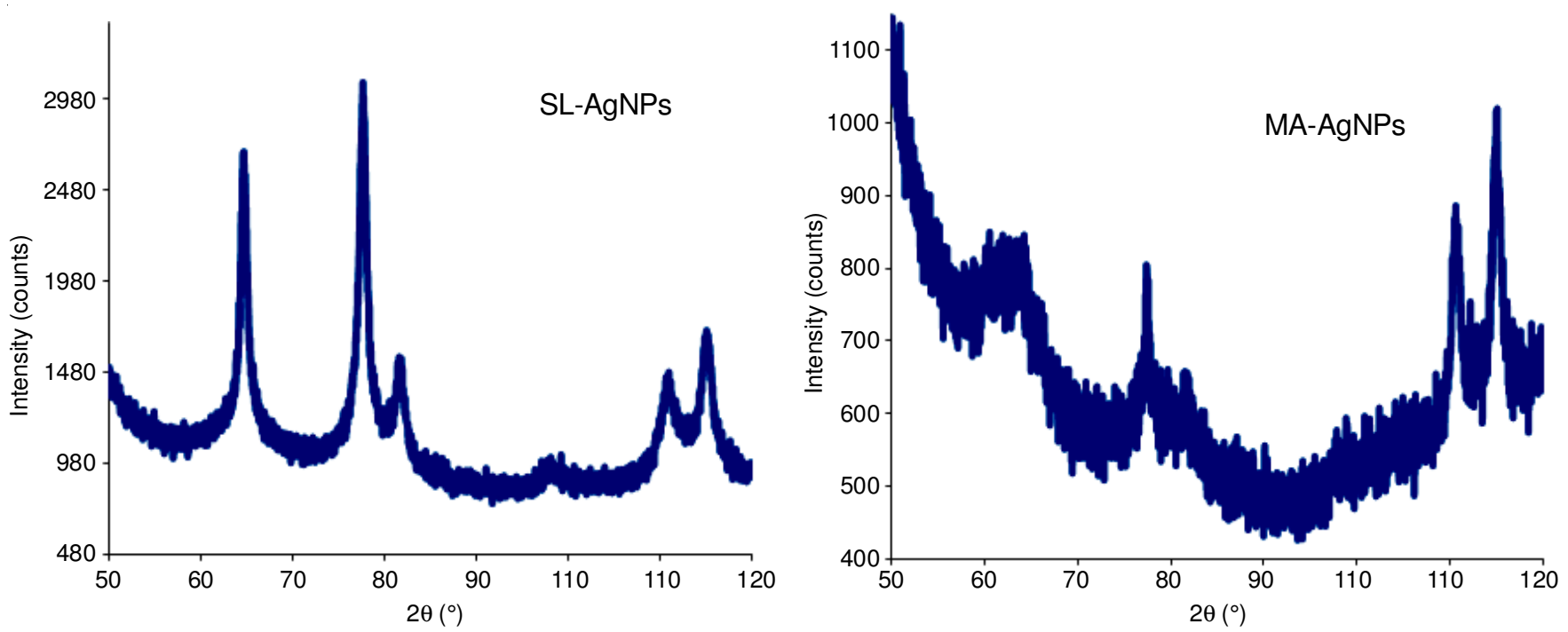

Fig. 6. X-ray diffraction pattern of synthesized silver nanoparticles of S. latifolius-AgNPs and M. acuminata-AgNPs 
which are present in the extracts, responsible for silver ions reduction and stabilization of resultant nanoparticles [46].

The free radical scavenging activity of the two synthesized silver nanoparticles of $S$. latifolius and $M$. acuminata was studied by their abilities to reduce the DPPH, a stable free radical. Any molecule that can donate an electron or hydrogen to DPPH can react with it and, thereby bleach the DPPH absorption. When DPPH accepts an electron donated by an antioxidant compound, the DPPH is decolourized, which can be measured quantitatively by changes in absorbance [47]. The SL-AgNPs and MA-AgNPs showed maximum activity of 66.78 and $58.20 \%$ respectively at the concentration of 500 $\mu \mathrm{g} / \mathrm{mL}$ whereas ascorbic acid and rutin at the same concentration exhibited 95.50 and $93.02 \%$ inhibition, respectively. The silver nanoparticles exhibited considerable DPPH free radical scavenging activity as indicated by their $\mathrm{IC}_{50}$ values as shown in Table-1. $\mathrm{IC}_{50}$ indicates the potency of scavenging activity, the lower the $\mathrm{IC}_{50}$, the higher the potency. Standard rutin and ascorbic acid were both found to have $\mathrm{IC}_{50}$ of 15.63 $\mu \mathrm{g} / \mathrm{mL}$, whereas SL-AgNPs and MA-AgNPs showed $\mathrm{IC}_{50}$ of 62.71 and 62.30, respectively. The synthesized nanoparticles exhibited not too good potential to act as free radical scavengers with $\mathrm{IC}_{50}$ for DPPH inhibition comparable to rutin and ascorbic acid which are known free radical scavengers.

TABLE-1

INHIBITORY CONCENTRATIONS ( $\left(\mathrm{IC}_{50}\right)$ OF SL-AgNPs AND MA-AgNPs FOR DPPH AND ABTS RADICAL SCAVENGING

\begin{tabular}{ccc}
\hline $\begin{array}{c}\text { Nanoparticles/ } \\
\text { standard }\end{array}$ & $\begin{array}{c}\mathrm{DPPH} \text { assay } \\
\mathrm{IC}_{50}(\mu \mathrm{g} / \mathrm{mL})\end{array}$ & $\begin{array}{c}\mathrm{ABTS} \text { assay } \\
\mathrm{IC}_{50}(\mu \mathrm{g} / \mathrm{mL})\end{array}$ \\
\hline SL-AgNPs & 62.71 & 129.64 \\
MA-AgNPs & 62.30 & 61.86 \\
Rutin & 15.63 & 23.64 \\
Vitamin C & 15.63 & 19.58 \\
\hline SL = Sarcocephalus latifolius; $\mathrm{MA}=$ Massularia acuminata
\end{tabular}

$\mathrm{SL}=$ Sarcocephalus latifolius $; \mathrm{MA}=$ Massularia acuminata

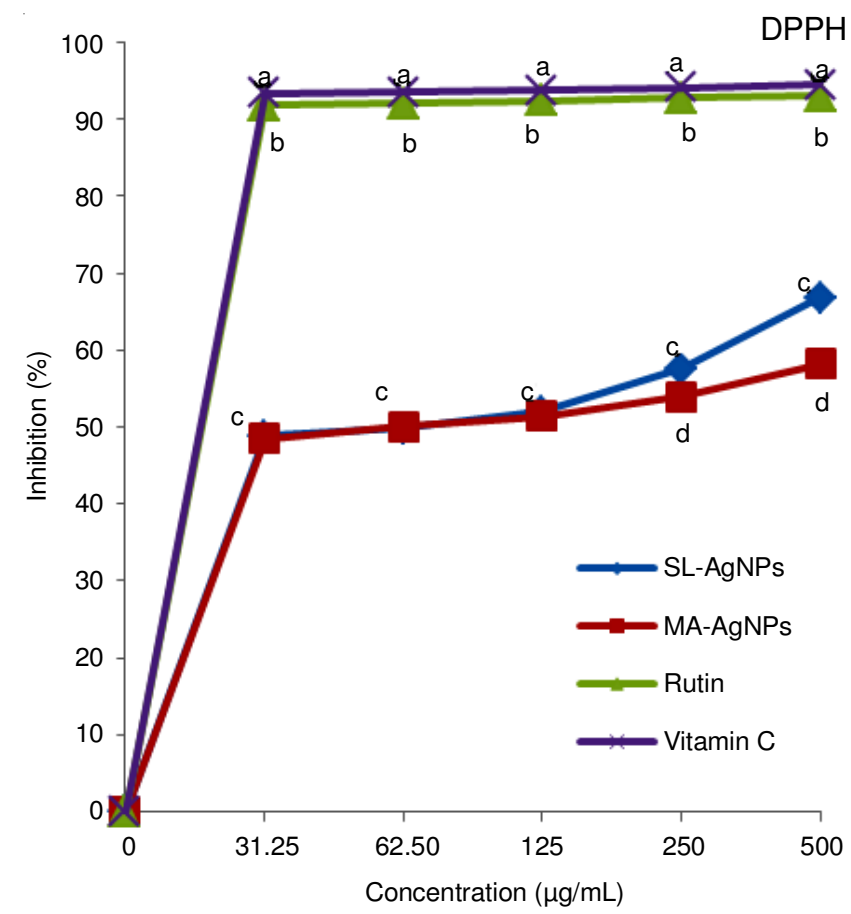

ABTS is a blue chromophore generated by the reaction of potassium persulphate with ABTS for 12-14 h in the dark. It is often used in phytomedicine research to measure the antioxidant properties of hydrogen-donating and chainbreaking of antioxidant agents. In this study, the synthesized silver nanoparticles and stansdard rutin and vitamin C scavenged the ABTS radical in a concentration dependent manner. SL-AgNPs and MA-AgNPs efficiently scavenged the ABTS radicals generated by the reaction between ABTS radical and ammonium persulphate (Table-1). The data obtained for both SL-AgNPs and MA-AgNPs showed potent antioxidant activity, but markedly lower in comparison to the standard drugs. The study demostrated the ability of the synthesized nanoparticles to scavenge radicals and thus suggest its usefulness as therapeutic agents for the treatment of diseases related with free radicals. The antioxidant assays for both DPPH and ABTS assays are shown in Fig. 7.

Nanomaterials are the leading requirements of the developing field of nanomedicine and biotechnology. Nanoparticles normally have better qualities than the bulk material of the same element, having immense surface relative to volume. Silver has been used for centuries for its antibacterial qualities; however, silver nanoparticles have proven to have better antibacterial activities than silver [48].

The agar dilution method was used to provide evidence for the antibacterial activity of synthesized nanoparticles of SL-AgNPS and MA-AgNPs against some selected Grampositive and Gram-negative pathogens. This method was employed because all the microorganisms are exposed equally to the tested samples at different concentrations. Synthesized silver nanoparticles displayed antibacterial activity against studied pathogenic microorganisms, with varying degree of concentrations between 250 and $15.63 \mu \mathrm{g} / \mathrm{mL}$ of the nanoparticles. The MICs of the synthesized nanoparticles is pre-

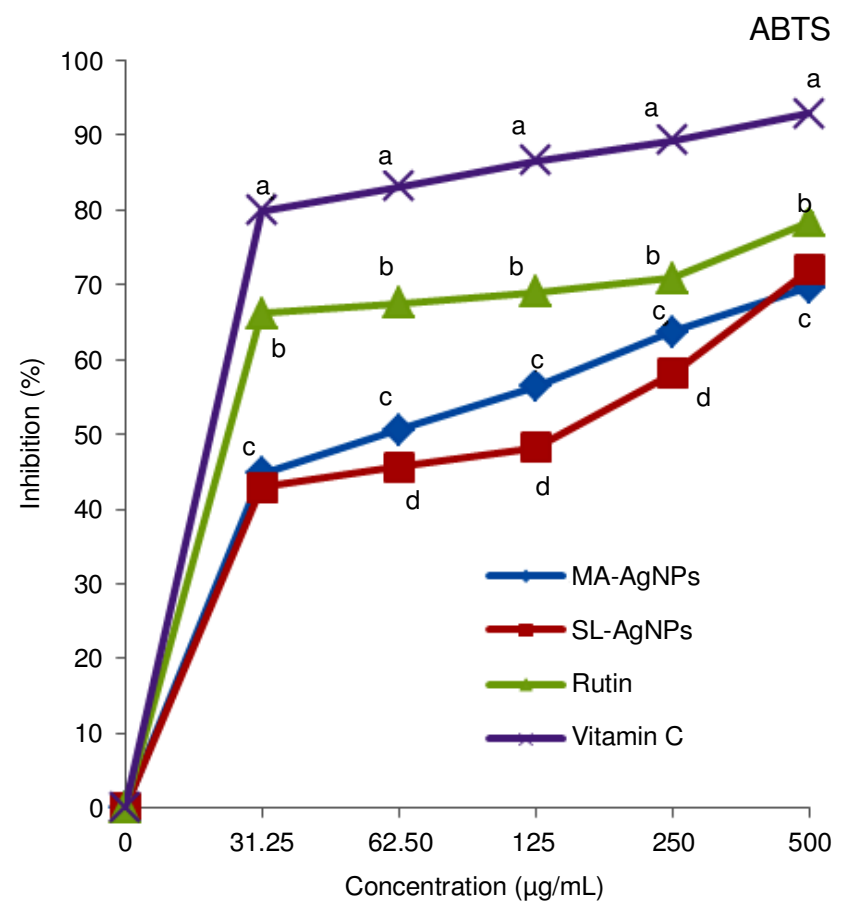

Fig. 7. Radical scavenging activities of silver nanoparticles and standard drugs against DPPH and ABTS. Values are means $\pm S D, n=3$. Means with different superscripts are significantly different $(\mathrm{P}<0.05)$ 
TABLE-2

MINIMUM INHIBITORY CONCENTRATIONS, MICs $(\mu \mathrm{g} / \mathrm{mL})$ OF SILVER NANOPARTICLES AND STANDARDS

\begin{tabular}{|c|c|c|c|c|}
\hline AgNPs/Standard drug & B. cereus & E. faecalis & E. coli & S. flexneri \\
\hline SL-AgNPs & $125 \pm 0$ & $125 \pm 0$ & $50 \pm 0$ & $250 \pm 0$ \\
\hline MA-AgNPs & $62.5 \pm 0$ & $62.5 \pm 0$ & $125 \pm 0$ & $125 \pm 0$ \\
\hline Ciprofloxacin & $<15.63 \pm 0$ & $<15.63 \pm 0$ & $31.25 \pm 0$ & $<15.63 \pm 0$ \\
\hline
\end{tabular}

sented in Table-2. The two synthesized nanoparticles were active on all the orgamisms tested. The highest activity against the tested bacteria was obtained with the MA-AgNPs with MICs of $62.5 \mu \mathrm{g} / \mathrm{mL}$ on both $B$. cereus and E. faecalis. The bacterial strains of E. coli and S. flexneri were as well sensitive to the nanoparticles, MA-AgNPs with equal MIC values of $125 \mu \mathrm{g} / \mathrm{mL}$. Similarly, SL-AgNPs displayed a consistent equal MIC value of $125 \mu \mathrm{g} / \mathrm{mL}$ both on B. cereus and E. faecalis, whereas E. coli and $S$. flexneri were both sensitive to the nanoparticles at MIC value of $250 \mu \mathrm{g} / \mathrm{mL}$. The MIC ranged from 62.5 to $250 \mu \mathrm{g} / \mathrm{mL}$ for all studied organisms while for ciprofloxacin, it ranged from 31.25 to $<15.63 \mu \mathrm{g}$ / $\mathrm{mL}$. These nanoparticles are therefore known to be biologically active. The antibacterial studies with SL-AgNPs and MA-AgNPs showed profound antibacterial effect against both Gram-positive and Gram-negative strains. The results of the present study suggests that the synthesized silver nanoparticles possess certain constituents with antibacterial properties that may be used as antibacterial agents in new drugs against common bacterial pathogens. Several underlying mechanisms on how silver nanoparticles works against microorganisms have been reported. Firstly, silver nanoparticles get attached to the negatively charged cell surface, altering the physical and chemical properties of the cell membranes and the cell wall. This action is known to destabilize important functions such as electron transport, osmoregulation, permeability and respiration of the cell [49-51]. Secondly, silver nanoparticles can permeate the cell, thereby interacting with DNA, proteins and protein-containing components $[49,52]$. Thirdly, silver nanoparticles release silver ions in order to cause an imbalance and generate amplified biocidal effects [52].

\section{Conclusion}

From this present study, it is concluded that even at very small concentration $(\mu \mathrm{g} / \mathrm{mL})$ silver nanoparticles from the stems of S. latifolius and M. acuminata possess very good antibacterial activity which makes them a potent source of antibacterial agents. Also, the synthesized SL-AgNPs and MA-AgNPs can potentially eliminate the problems of chemical agents in the environment that may pose adverse effects on the ecosystem, thus making nanoparticles more eco-friendly. Furthermore, the synthesized silver nanoparticles enhance the therapeutic efficacies and strengthened the medicinal potentials of $S$. latifolius and $M$. acuminata. Lastly, both $S$. latifolius and M. acuminata are used as chewing sticks, an alternative to toothbrushes. Using them as chewing sticks in their nanoparticles form will bring about good and better hygiene to the tooth cavities. This, of course, will be subject to further studies to ascertain how it should be effectively applied.

\section{ACKNOWLEDGEMENTS}

The authors are thankful to Govan Mbeki Research \& Development Centre, University of Fort Hare for funding this project.

\section{REFERENCES}

1. V.K. Sharma, R.A. Yngard and Y. Lin, Adv. Colloid Interface Sci., 145, 83 (2009);

https://doi.org/10.1016/j.cis.2008.09.002.

2. A. Nanda and M. Saravanan, Nanomedicine: Nanotechnol. Biol. Med., 5, 452 (2009); https://doi.org/10.1016/j.nano.2009.01.012.

3. A. Ahmad, P. Mukherjee, S. Senapati, D. Mandal, M.I. Khan, R. Kumar and M. Sastry, Colloids Surf. B Biointerfaces, 28, 313 (2003); https://doi.org/10.1016/S0927-7765(02)00174-1.

4. A.K. Jha, K. Prasad, V. Kumar and K. Prasad, Biotechnol. Prog., 25, 1476 (2009); https://doi.org/10.1002/btpr.233.

5. C. Krishnaraj, E.G. Jagan, S. Rajasekar, P. Selvakumar, P.T. Kalaichelvan and N. Mohan, Colloids Surf. B Biointerfaces, 76, 50 (2010); https://doi.org/10.1016/j.colsurfb.2009.10.008.

6. K. Natarajan, S. Selvaraj and M.V. Ramachandra, Dig. J. Nanomater. Biostruct., 5, 135 (2010).

7. P. Mohanpuria, N.K. Rana and S.K. Yadav, J. Nano. Res., 10, 507 (2008); https://doi.org/10.1007/s11051-007-9275-X.

8. J.S. Valli and B. Vaseeharan, Mater. Lett., 82, 171 (2012); https://doi.org/10.1016/j.matlet.2012.05.040.

9. V. Kumar and S.K. Yadav, J. Chem. Technol. Biotechnol., 84, 151 (2009); https://doi.org/10.1002/jctb.2023.

10. V. Gopinath, D.M. Ali, S. Priyadarshini, N.M. Priyadharsshini, N. Thajuddin and P. Velusamy, Colloids Surf. B Biointerfaces, 96, 69 (2012); https://doi.org/10.1016/j.colsurfb.2012.03.023.

11. D.M. Ali, N. Thajuddin, K. Jeganathan and M. Gunasekaran, Colloids Surf. B Biointerfaces, 85, 360 (2011); https://doi.org/10.1016/j.colsurfb.2011.03.009.

12. T.C. Prathna, N. Chandrasekaran, A.M. Raichur and A. Mukherjee, Colloids Surf. B Biointerfaces, 82, 152 (2011); https://doi.org/10.1016/j.colsurfb.2010.08.036.

13. M. Sathishkumar, K. Sneha, S.W. Won, C.-W. Cho, S. Kim and Y.-S. Yun, Colloids Surf. B Biointerfaces, 73, 332 (2009); https://doi.org/10.1016/j.colsurfb.2009.06.005.

14. A. Bankar, B. Joshi, A.R. Kumar and S. Zinjarde, Colloids Surf. A Physicochem. Eng. Asp., 368, 58 (2010); https://doi.org/10.1016/j.colsurfa.2010.07.024.

15. A. Nabikhan, K. Kandasamy, A. Raj and N.M. Alikunhi, Colloids Surf. B Biointerfaces, 79, 488 (2010); https://doi.org/10.1016/j.colsurfb.2010.05.018.

16. S.T. Magili, H.M. Maina, J.T. Barminas and I. Toma, Merit Res. J. Environ. Sci. Toxicol., 2, 120 (2014).

17. O. Baidya, S. Chaudhuri and K. Devi, Int. Res. J. Med. Sci., 2, 13 (2014); https://doi.org/10.5455/2320-6012.ijrms20140203.

18. J.Abbah, S. Amos, B. Chindo, I. Ngazal, H.O. Vongtau, B. Adzu, T. Farida, A.A. Odutola, C. Wambebe and K.S. Gamaniel, J. Ethnopharmacol., 127, 85 (2010); https://doi.org/10.1016/j.jep.2009.09.045.

19. E.O. Ogunlana and E. Ramstad, Planta Med., 27, 354 (1975); https://doi.org/10.1055/s-0028-1097814.

20. I.I. Madubunyi, J. Herbs Spices Med. Plants, 3, 23 (1996); https://doi.org/10.1300/J044v03n02 04.

21. Z.A.M. Nworgu, D.N. Onwukaeme, A.J. Afolayan, F.C. Ameachina and B.A. Ayinde, Afr. J. Pharm. Pharmacol., 2, 37 (2008). 
22. L. Tona, K. Kambu, K. Mesia, K. Cimanga, S. Apers, T. De Bruyne, L. Pieters, J. Totté and A.J. Vlietinck, Phytomedicine, 6, 59 (1999); https://doi.org/10.1016/S0944-7113(99)80036-1.

23. J.A. Akande and Y. Hayashi, World J. Microbiol. Biotechnol., 14, 235 (1998); https://doi.org/10.1023/A:1008838331079.

24. P.O. Bankole, A.A. Adekunle, R.T. Oyede, F. Faparusi and A. Adewole, Int. J. Appl. Sci. Technol., 2, 131 (2012).

25. R. Bairwa, P. Gupta, V.K. Gupta and B. Srivastava, Int. J. Pharm. Chem. Sci., 1, 1529 (2012).

26. K.C. Ndukwe, I.N. Okeke, A. Lamikanra, S.K. Adesina and O. Aboderin, J. Contemp. Dent. Pract., 3, 86 (2005).

27. C.D. Wu, I.A. Darout and N. Skaug, J. Periodontal Res., 36, 275 (2001); https://doi.org/10.1034/j.1600-0765.2001.360502.x.

28. D.J. Huang, B.X. Ou and R.L. Prior, J. Agric. Food Chem., 53, 1841 (2005); https://doi.org/10.1021/jf030723c.

29. S.W. Odeyemi, A.J. Afolayan and G. Bradley, Ph.D. Thesis submitted in the Department of Biochemistry and Microbiology, University of Fort Hare, South Africa (2016).

30. R. Re, N. Pellegrini, A. Proteggente, A. Pannala, M. Yang and C. RiceEvans, Free Radic. Biol. Med., 26, 1231 (1999); https://doi.org/10.1016/S0891-5849(98)00315-3.

31. National Committee for Clinical Laboratory Standards, Procedures for the Handling and Transport of Diagnostic Specimens and Etiologic Agent, Approved Standard, NCCLS Document H5-A3, Wayne, PA: NCCLS, edn 3 (1994).

32. K. Chitra and G. Annadurai, BioMed Res. Int., 2014, 1 (2014); https://doi.org/10.1155/2014/725165.

33. F.A. Farghaly and N.A. Nafady, J. Agric. Sci., 7, 277 (2015); https://doi.org/10.5539/jas.v7n11p277.

34. G. Singhal, R. Bhavesh, K. Kasariya, A.R. Sharma and R.P. Singh, J. Nano Res., 13, 2981 (2011); https://doi.org/10.1007/s11051-010-0193-y.

35. N. Basavegowda, A. Idhayadhulla and Y.R. Lee, Mater. Lett., 129, 28 (2014);

https://doi.org/10.1016/j.matlet.2014.05.008.

36. P. Velmurugan, S. Lee, M. Iydroose, K. Lee and B. Oh, Appl. Microbiol. Biotechnol., 97, 361 (2013); https://doi.org/10.1007/s00253-012-3892-8.
37. J. Li, J. Zhu and X. Liu, Dalton Trans., 43, 132 (2014); https://doi.org/10.1039/C3DT52242C.

38. I.D.G. Macdonald and W.E. Smith, Lagmuir, 12, 706 (1996); https://doi.org/10.1021/la950256w.

39. D.M. Ali, M. Sasikala, M. Gunasekaran and N. Thajuddin, Dig. J. Nanomater. Biostruct., 6, 385 (2011).

40. K. Nakamoto, Infrared and Raman Spectra of Inorganic and Coordination Compounds, Wiley, New York, edn 5 (1997).

41. S. Agarwal, D. Patidar and N.S. Saxena, J. Appl. Polym. Sci., 123, 2431 (2012); https://doi.org/10.1002/app.34800.

42. H.M.M. Ibrahim, J. Radiat. Res. Appl. Sci., 8, 265 (2015); https://doi.org/10.1016/j.jrras.2015.01.007.

43. P. Magudapathy, P. Gangopadhyay, B.K. Panigrahi, K.G.M. Nair and S. Dhara, Physica B, 299, 142 (2001); https://doi.org/10.1016/S0921-4526(00)00580-9.

44. R.R. Banala, V.B. Nagati and P.R. Karnati, Saudi J. Biol. Sci., 22, 637 (2015); https://doi.org/10.1016/j.sjbs.2015.01.007.

45. T. Maneerung, S. Tokura and R. Rujiravanit, Carbohydr. Polym., 72, 43 (2008); https://doi.org/10.1016/j.carbpol.2007.07.025.

46. S.M. Roopan, G. Rohit, G. Madhumitha, A.A. Rahuman, C. Kamaraj, A. Bharathi and T.V. Surendra, Ind. Crops Prod., 43, 631 (2013); https://doi.org/10.1016/j.indcrop.2012.08.013.

47. L.L. Mensor, F.S. Menezes, G.G. Leitão, A.S. Reis, T.C. Santos, C.S. Coube and S.G. Leitão, Phytother. Res., 15, 127 (2001); https://doi.org/10.1002/ptr.687.

48. T. Theivasanthi and M. Alagar, Nano Biomed. Eng., 4, 58 (2012); https://doi.org/10.5101/nbe.v4i2.p58-65.

49. A.E. Nel, L. Madler, D. Velegol, T. Xia, E.M.V. Hoek, P. Somasundaran, F. Klaessig, V. Castranova and M. Thompson, Nat. Mater., 8, 543 (2009); https://doi.org/10.1038/nmat2442.

50. S. Mingyu, H. Fashui, L. Chao, W. Xiao, L. Xiaoqing, C. Liang, G. Fengqing, Y. Fan and L. Zhongrui, Biol. Trace Elem. Res., 118, 120 (2007); https://doi.org/10.1007/s12011-007-0006-Z.

51. I. Sondi and B. Salopek-Sondi, J. Colloid Interface Sci., 275, 177 (2004); https://doi.org/10.1016/j.jcis.2004.02.012.

52. C. Marambio-Jones and E.M.V. Hoek, J. Nano. Res., 12, 1531 (2010); https://doi.org/10.1007/s11051-010-9900-y. 